\title{
Role and productivity of white corn in the reclamation of saline soils of Uzbekistan
}

\author{
Botir Tukhtashev ${ }^{1, *}$, Chingizkhon Toshpulatov ${ }^{1}$, Makhkam Shadmonov $^{1}$, and Nematilla \\ Khudaybergenov ${ }^{1}$ \\ ${ }^{1}$ Tashkent State Agrarian University, University str., 2, Tashkent province, 100140 Uzbekistan
}

\begin{abstract}
The issue of growing white corn in saline soils and increasing its resistance to salt remains a topical issue. The fact that the soils of the experiment area have a certain degree of salinity, that saline washing operations are not carried out at the required level, and that there is a seasonal salt accumulation process indicates a certain complexity of the problem. To address this issue, research was conducted in the saline soils of the Ak altyn district of Syrdarya province in Uzbekistan. Under poorly saline soils, the average yield of white oats was $669.6 \mathrm{q} / \mathrm{ha}$, while the average saline soils yielded $580.7 \mathrm{q} / \mathrm{ha}$.
\end{abstract}

\section{Introduction}

In recent years, a lot of work has been done in Uzbekistan in the field of saline land reclamation $[1,3,4]$. The reclamation of saline lands and the technology of cultivation of field crops on them are regularly studied and brought to the level of state importance. Caring for each field crop based on specific soil and climatic conditions is a guarantee of high and quality yields [2, 6-9].

In amelioration, it is impossible to leave an irrigated field open all year round without planting crops, leaving the ground open without planting during the year or during the hottest time of the year can lead to overheating of the soil and excessive evaporation of water from the soil surface. This process raises groundwater levels and leads to adverse conditions such as re-salinization and swamping of soils $[3,5,11]$. Therefore, in saline soils, it is not possible from an agricultural point of view to leave the field uncultivated. Under such conditions, crops should be selected in such a way that their biomass covers the soil surface throughout the year or at the hottest time of the year [5]. At the same time, in the conditions of these soils, the issue of growing field crops resistant to soil salinity and increasing their resistance to salt remains a topical issue. At a time when agriculture is developing, it is important to increase the adaptability and resistance of field crops to saline soils on the basis of the use of advanced technologies, as well as to pay special attention to soil reclamation $[6,8,10]$.

During the visit of the President of Uzbekistan to Syrdarya province in May 2017 and April 2018, the enterprise "Bek Cluster" was established, where it is planned to grow 80,000 tons of food crops. It is also planned to implement a project on the production of

\footnotetext{
${ }^{*}$ Corresponding author: botir.tukhtashev@yandex.com
} 
special fodder in Syrdarya district. In order to implement the above projects, the Syrdarya province needs a type of crop that is resistant to salinity, produces high biomass, protects the soil surface from overheating during the hottest period of the year and, most importantly, provides nutritious fodder. One of these crops which has been rarely used in recent years is white corn.

The total irrigated area of Syrdarya province is 266,700 hectares $(80 \%)$, which are saline to varying degrees, of which $39.8 \%$ are weak, $30.4 \%$ are moderate, $6.4 \%$ are strong, and $2.7 \%$ are very strongly saline. Efficient use of these lands requires the introduction of technologies for growing crops resistant to salinity in the current conditions of water scarcity $[4,12]$.

The salinity of the soils of the study area (weak, moderate and strongly saline), the lack of saline leaching and the presence of a seasonal salt accumulation process indicate that the problem is solved from a scientific point of view and complexity.

\section{Materials and methods}

The study was conducted on the farm of "Jahongir Muhammad Ali" in Ak Altyn district of Syrdarya province. In the experiment, a variety of white corn "Karabosh" was planted. Plant height 220-250 cm, growing season 105-110 days, resistant to soil salinity and drought, grain yield 2.2-2.5 tons/ha. The silage mass of the crop is 35-39 tons/ha in the first harvest, 20-25 tons/ha in the second harvest and a total of 55-60 tons/ha.

The field experiment was conducted in 4 repetitions. The options are arranged in a single tier. Furrow length is $50 \mathrm{~m}$, each variant is taken in 8 rows, at the expense of one visit of the drill $\left(50 \times 7.2=360 \mathrm{~m}^{2}\right)$. The total area of each plot is $360 \mathrm{~m}^{2}$ and the calculated area is $180 \mathrm{~m}^{2}$. Therefore, the total area of the experiment is $4,320 \mathrm{~m}^{2}$ and the calculated area is $2,160 \mathrm{~m}^{2}$.

Samples were taken and sent to the laboratory for analysis to determine the amount of NPK, general and mobile forms, humus in the layer of $0-30 \mathrm{~cm}$ and $30-50 \mathrm{~cm}$ before planting on the drive, subsoil layers of soil. Soil moisture and agrochemical analyzes were performed using new laboratory instruments acquired during the project implementation (Fig. 1).

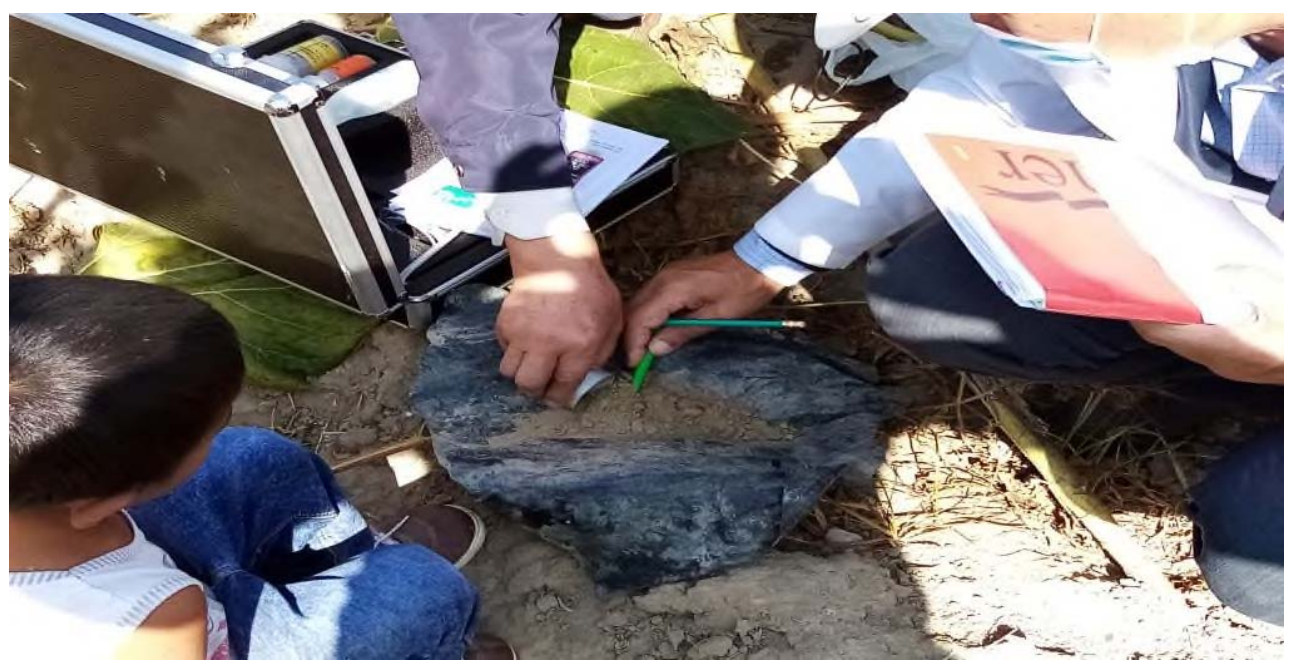

Fig. 1. Process of taking a soil sample from the field for soil moisture and agrochemical analysis before conducting the study. 
The following calculations were performed in the experiment: The volume mass of the soil is determined by taking soil samples in which the natural state is not disturbed. Soil water permeability developed by the Uzbek Scientific Research Institute of Cotton by the 6hour step method. Soil moisture is determined before and after each watering by the method of drying in a thermostat. The amount of water supplied to the field.

\section{Results and discussion}

Experimental field soils were washed with saline in the fall. Prior to the saline wash, we reviewed the condition of the ditch at the site where the field experiment will be conducted. The depth of the ditch is $2.8 \mathrm{~m}$. In practice, in the case of moderately saline soils, saline leaching is carried out using $2,000 \mathrm{~m}^{2}$ to $4,000 \mathrm{~m}^{2}$ of water. Given the limited water resources in the experimental field, the soil was washed with saline at a rate of 2,500 $\mathrm{m}^{3}$ of water at a time. In Mirzachul conditions, we calculated the amount of salt present in the soil before saline leaching and after saline leaching on the dry residue and chloride ion. This means that the amount of chlorine in the $0-100 \mathrm{~cm}$ layer is $0.187 \%$ before the washing of the soil saline, and $0.32 \%$ after the washing of the soil saline. Hence, the saline wash efficiency was 5.8 in the experiment.

To increase the efficiency of saline washing, the followings were done:

1) The field is very well leveled before saline washing (if the ground is not flat, more salt accumulates in the slightly elevated and slightly lower part of the microrelief, saline washing is not of good quality, soil does not moisten evenly under the influence of irrigation water, more water is used for irrigation);

2) Salt leaching was carried out when the groundwater level was deep;

3) The experimental field was treated immediately with brine washing and soil compaction. The purpose of this is to prevent the destruction of soil capillaries and the rise of water.

It is necessary to ensure that the mineralized water formed during the saline washing process flows away. Increasing these measures will achieve the goal observed in saline washing.

In the experiment, oats were planted when the soil temperature was $12-14{ }^{\circ} \mathrm{C}$ in a layer of $0-10 \mathrm{~cm}$. The sowing rate is $15 \mathrm{~kg}$ per hectare. This norm is enough for 500,000 bushes of corn per hectare. This planting rate is the optimal rate for multi-crop oats grown for blue mass. This plant accumulates, so it is advisable to plant it sparsely and re-grow after harvesting. In the experiment, the seedlings were obtained at the expense of the natural moisture of the soil.

The young shoots of multi-crop corn are very delicate and very sensitive to soil compaction. Therefore, as soon as the oats germinate and the rows of plants appear, the processing between the rows begins immediately.

Oats were cultivated 2 times between rows during the period of growth and development in order to eliminate weeds that grew between the rows. In the first cultivation, row spacing was loosened to a depth of 6-8 cm, then $12-14 \mathrm{~cm}$. After the first cultivation, $100 \mathrm{~kg}$ of nitrogen per hectare and $30 \mathrm{~kg}$ of phosphorus fertilizer were applied. In the second intercropping, $60 \mathrm{~kg}$ of nitrogen and $30 \mathrm{~kg}$ of phosphorus were applied per hectare. Thus, $160 \mathrm{~kg}$ of nitrogen and $60 \mathrm{~kg}$ of phosphorus fertilizer were given during the corn growing season.

The optimal irrigation rate for oats was determined based on soil moisture. The number of irrigations was set for the green mass 6 times during the growing season, 3 times before each harvest. At this irrigation rate, the soil moisture did not fall below $75-80 \%$ of the limited field moisture capacity (LFMC) until the oats sprouted. During the growing season, 
the first watering was started when the plant produced 5-6 leaves, which coincided with the May 28, and 16-18 days later, the second watering was carried out on June 14-16. In the first and second irrigation, the irrigation rate was increased by $20-25 \%$ due to the fact that the corn grass is still young and the salts in the soil are more likely to destroy the plant grass. Irrigation rate was determined based on LFMC and was $800-1000 \mathrm{~m}^{3} / \mathrm{ha}$.

An increase in the amount of salt in the soil begins to manifest itself in the early developmental stages of plant seeds. When growing white oats in moderately and strongly saline soils, it is necessary to take measures to get the seeds evenly without salting them. Therefore, it is necessary to sow corn seeds at an early stage and get a full seedling. In practice, it is safe to say that the amount of salt in moderately saline soils led to the late formation of seedlings.

Observation of the germination of corn seeds under weakly saline soils was carried out in the following order. We took into account the germination of seeds every 2 days. In 10 days of sowing, 59.5 out of 250 seeds germinated, 122.2 out of 250 seeds germinated in the observations made on May 13 2019, 182.5 out of 250 observations on May 152019 and finally 238.5 out of 23 observations in May 172019.

The dynamics of sorghum germination under moderately saline soils was as follows. It was noted that 51 seeds germinated in the observations on May 12 2019, 100.1 in the observations on May 16 2019, 147 in the observations on May 202019 and finally 201 in the observations on May 24 2019. In general, in moderately saline soils, the initial effect of salt on a uniform germination of seeds began to be felt, and only 201 out of 250 seeds germinated.

The initial and complete period of corn germination was observed. Observations began on July 7, 2019. The plant began to germinate within 10-15 days after tubing. At the same time, the plants that were included in the first reed wrapping were the first to emerge and began to take it into account.

Observations of the entry of corn into the flowering phase were also carried out in the same order as the process of entry of the plant into the initial phases, based on the conditions of weak and moderately saline soils. Hence, the observations were started on the plants that produced the full range, and the observation time was recorded as above. Thus, the corn began to bloom from 7-9 days after emergence. The period when the corn began to bloom was 84-87 days after planting.

The entry of corn into the accumulation phase was also observed in the iteration 4 under weak and moderately saline soils in terms of net area unit. In this case, as observed in the germination of the plant, calculations were made in the calculated area in each variant. The plants in each iteration were labeled, and subsequent calculations were also performed on these plants. When observing the entry into the accumulation phase, it was observed that the plant emerges from the root collar, the stem from which the first shoots sprouted. In this case, observations were made every 2 days.

The entry of 50,75 and $100 \%$ of the corn into the accumulation phase continued in the same order. In the study, the entry of the corn into the full accumulation phase occurred on June 10 2019, and this occurred in 37-38 days.

In strongly saline soils, when the salt content was $0.5-2.0 \%$ of the dry weight of the soil, it was observed that the seeds did not germinate at the same time, while the weak ones were destroyed in the first period. This has an effect on the subsequent growth and development of the plant.

As white corn increased its salt content in the soil, its sensitivity to salt also changed. Under weakly saline soils, no significant change in accumulation was observed when the salt content was $0.3-0.5 \%$ by weight of dry soil, all germinated plants were evenly accumulated, and healthy seedlings were formed. However, an increase in the salt concentration in the soil to $0.5-1.0 \%$ of the dry weight of the soil during the initial 
development of the plant delayed the entry of white corn into the accumulation phase by an average of 4-5 days in the crop section, also negatively affecting the number of seedlings collected. In general, this pattern was observed and maintained during the entry of corn into the later stages of development (Table 1).

Table 1. Conducting biometric calculations on corn was planted on May 12019.

\begin{tabular}{|c|c|c|c|c|c|c|c|}
\hline \multirow{3}{*}{$\#$} & \multirow{2}{*}{ Iterations } & \multicolumn{7}{|c|}{ In weakly saline soils } \\
\cline { 3 - 8 } & & June 1, 2019 & \multicolumn{2}{|c|}{ July 1, 2019 } & \multicolumn{2}{c|}{ August 1, 2019 } \\
\cline { 2 - 8 } & $\begin{array}{c}\text { Plant } \\
\text { height }\end{array}$ & $\begin{array}{c}\text { No. of } \\
\text { leaves }\end{array}$ & $\begin{array}{c}\text { Plant } \\
\text { height }\end{array}$ & $\begin{array}{c}\text { No. of } \\
\text { leaves }\end{array}$ & $\begin{array}{c}\text { Plant } \\
\text { height }\end{array}$ & $\begin{array}{c}\text { No. of } \\
\text { leaves }\end{array}$ \\
\hline 1 & Iteration 1 & 19.4 & 4.6 & 98.7 & 13.5 & 183.9 & 15.9 \\
\hline 2 & Iteration 2 & 17.6 & 4.4 & 95.4 & 13.0 & 179.5 & 14.3 \\
\hline 3 & Iteration 3 & 15.4 & 3.8 & 90.5 & 11.6 & 170.6 & 13.2 \\
\hline 4 & Iteration 4 & 13.7 & 3.0 & 86.0 & 9.8 & 166.7 & 12.0 \\
\hline 5 & Average & $68.1: 4=$ & $15.8: 4=$ & $373.6: 4$ & $49.9: 4=$ & $703.7: 4$ & $56.4: 4$ \\
& & 17.0 & 3.95 & $=93.4$ & 12.5 & $=175.8$ & $=14.1$ \\
\hline & & \multicolumn{7}{|c|}{ In moderately saline soils } \\
\hline 1 & Iteration 1 & 15.5 & 4.0 & 78.5 & 10.1 & 158.0 & 13.0 \\
\hline 2 & Iteration 2 & 16.0 & 3.5 & 79.3 & 9.5 & 145.5 & 12.8 \\
\hline 3 & Iteration 3 & 14.6 & 3.0 & 81.0 & 8.5 & 141.7 & 12.1 \\
\hline 4 & Iteration 4 & 14.0 & 3.1 & 74.5 & 9.2 & 144.6 & 11.6 \\
\hline & Average & $60.1: 4=$ & $13.6: 4=$ & $313.3: 4$ & $37.3: 4$ & $589.8: 4$ & $49.5: 4$ \\
& & 15.0 & 3.4 & $=78.2$ & $=9.3$ & $=147.4$ & $=12.3$ \\
\hline & & \multicolumn{7}{|c|}{ In strongly saline soils } & \\
\hline 1 & Iteration 1 & 11.0 & 2.1 & 32.0 & 3.9 & 32.0 & 3.9 \\
\hline 2 & Iteration 2 & 6.5 & 2.6 & 26.5 & 5.8 & 26.5 & 5.8 \\
\hline 3 & Iteration 3 & 8.6 & 3.3 & 33.7 & 7.1 & 33.7 & 7.1 \\
\hline 4 & Iteration 4 & 10.0 & 4.9 & 47.8 & 6.3 & 47.8 & 6.3 \\
\hline & Average & $36.1: 4$ & $12.9: 4=$ & $140.0: 4$ & $23.1: 4$ & $140.0: 4$ & $23.1: 4$ \\
& $=9.0$ & 3.2 & $=35.0$ & $=5.7$ & $=35.0$ & 5.7 \\
\hline
\end{tabular}

This means that a month after planting oats in the 1st harvest or on the 15 th or 16 th day of germination, the plant height was $19.4 \mathrm{~cm}$ and the 5 th leaf germination started. The leaf was 13.5 in the corresponding position, and finally in the third period in which biometric calculations were performed on the plant, on August 1, the plant was $183.9 \mathrm{~cm}$ tall and the number of leaves was 15.9. Similar data were obtained on the growth and development of oats in the remaining iterations. However, in the biometric calculations performed three times in the fourth turn, certain differences in plant height and leaf number were observed. This can be explained by the partial disruption of agro-technical measures carried out during the development of the plant. In general, in the biometric calculations conducted on July 1 on the iteration 4, the plant produced $86.6 \mathrm{~cm}$ of leaves and 9.6 leaves, while in the calculations at the end of the growing season it produced $166.7 \mathrm{~cm}$ in height and 12.0 leaves, respectively (Table 1).

It was noted in the study that a certain difference was observed in the biometric calculations of corn under weak and moderately saline soils. In particular, the effect of salt was evident in the early development of the plant, which also had a negative effect in the later developmental phases. In particular, in moderately saline soils, plant height was 15.0 $\mathrm{cm}$ in biometric calculations on June $12019,78.2 \mathrm{~cm}$ on July 12019 , and finally $146.6 \mathrm{~cm}$ on August 1 2019, significantly lagging behind plants grown in weakly saline variants was observed. This situation certainly did not go unnoticed in its impact on productivity.

Biometric calculations performed on oats in the section of strongly saline soils yielded completely different information. In these iterations, the harmful effects of salt in the soil were evident in the early stages of plant development, adversely affecting plant 
development. Wet mass and dry mass of oats taken from the calculated area were also calculated in the calculation of corn yield.

Thus, the wet mass obtained in the iteration 1 is $36,000 \mathrm{~g}$ or $36 \mathrm{~kg}$, the yield from the second iteration is $34,500 \mathrm{~g}$ or $34.5 \mathrm{~kg}$, the wet mass from the third iteration is $32,200 \mathrm{~g}$ or $32.2 \mathrm{~kg}$, and finally the wet mass from the fourth iteration is $30,950 \mathrm{~g}$ or $30.9 \mathrm{~kg}$. Overall, the wet mass obtained on iteration 4 averaged $33,412 \mathrm{~g}$ or $33.4 \mathrm{~kg}$ (Table 2).

Table 2. Calculation of blue mass of oats and dry silage yield.

(Given in the 2nd harvest)

\begin{tabular}{|c|c|c|c|c|c|c|c|}
\hline \multirow{2}{*}{ \# } & \multirow{2}{*}{ Iterations } & \multirow{2}{*}{$\begin{array}{l}\text { No. of } \\
\text { plants } \\
\text { in one } \\
\text { hectare }\end{array}$} & \multirow{2}{*}{$\begin{array}{c}\text { No. of } \\
\text { plants } \\
(16.6 \text { p.m) }\end{array}$} & \multicolumn{2}{|c|}{ Productivity, $g$} & \multicolumn{2}{|c|}{ Productivity, q/ha } \\
\hline & & & & Wet mass & Dry mass & Wet mass & Dry mass \\
\hline \multicolumn{8}{|c|}{ In weakly saline soils } \\
\hline 1. & Iteration 1 & 500,000 & 250 & 36,000 & 9000 & 675.3 & 180.5 \\
\hline 2. & Iteration 2 & 500,000 & 250 & 34,500 & 8500 & 660.7 & 173.1 \\
\hline 3. & Iteration 3 & 500,000 & 250 & 32,200 & 8100 & 687.3 & 160.8 \\
\hline 4. & Iteration 4 & 500,000 & 250 & 30,950 & 7500 & 655.4 & 155.1 \\
\hline & Average & & & $\begin{array}{c}133650: 4 \\
=33412\end{array}$ & $\begin{array}{c}33100: 4 \\
=8275\end{array}$ & $\begin{array}{c}2678.7: 4= \\
669.6\end{array}$ & $\begin{array}{c}678.5: 4=1 \\
69.6\end{array}$ \\
\hline \multicolumn{8}{|c|}{ In moderately saline soils } \\
\hline 1 & Iteration 1 & 500,000 & 250 & 28750 & 7187 & 575 & 125.5 \\
\hline 2 & Iteration 2 & 500,000 & 250 & 29600 & 7400 & 590 & 132.4 \\
\hline 3 & Iteration 3 & 500,000 & 250 & 28400 & 7250 & 572 & 121.5 \\
\hline 4 & Iteration 4 & 500,000 & 250 & 29480 & 7180 & 585 & 126.6 \\
\hline & Average & & & $\begin{array}{l}116230: 4 \\
=29057.5\end{array}$ & $\begin{array}{l}29017: 4 \\
=7254.5\end{array}$ & $\begin{array}{c}2322: 4= \\
580.7\end{array}$ & $\begin{array}{l}506.0: 4 \\
=126.5\end{array}$ \\
\hline
\end{tabular}

The calculation of the dry mass yield (silage) of oats was carried out in the same order. In this case, first the options were calculated, and then the average yield. Thus, the yield of silage in the first turn was 675.3 quintal (q)/ha, in the second turn $-660.7 \mathrm{q} / \mathrm{ha}$, in the third turn $-687.3 \mathrm{q} / \mathrm{ha}$, and in the fourth turn $-655.4 \mathrm{q} / \mathrm{ha}$. The average yield of oats in the study was $669.6 \mathrm{q} / \mathrm{ha}$.

In the cross-section of moderately saline soils, slightly lower yields were obtained than in variants and iterations in weakly saline soils. In the above analysis, we tried to explain the reasons for this. In particular, the mass of oats in the calculated area was 29,057.5 g, which is $4,355 \mathrm{~g}$ less than the variant in weakly saline soils, or the total yield in these soils was $580.7 \mathrm{q} / \mathrm{ha}$.

In studies of strongly saline soils of the Syrdarya province, the effect of salt in the soil was felt very strongly during the initial development of the plant, and the plants in the variant and iteration died without growing. Yields from most overgrown plants were very low.

In the study, when observing the phenology of oats planted in strongly saline soils, it was noted that $650-700$ out of every 1,000 seeds died. Also, the seedlings that sprouted here and there of the plot perished under the influence of the intensity of salinity before reaching the next phases. 


\section{Conclusions}

In conclusion, it should be noted that in the future in the conditions of these soils it is advisable to carry out measures aimed primarily at soil reclamation, salt washing and consistent implementation of reclamation measures that reduce its harmful effects on the soil. Particular attention should be paid to the technology of proper use of saline soils and the proper use of these soils in meeting the needs of livestock for fodder. We believe that these measures should be implemented without delay and measures should be taken for the efficient use of land.

\section{References}

1. Y. Peng, F. Li, N. Xu, R. Kulmatov, K. Gao, G. Wang, Y. Zhang, Y. Qiao, Y. Li, H. Yang, S. Hao, Q. Li, S. Khasanov, Chinese Journal of Eco-Agriculture, 29(2), 312-324 (2021)

2. M. Bomb, Scientists of Lviv State Agrarian University of Production, 5, 28-30 (2005)

3. S. Isaev, S. Khasanov, Y. Ashirov, A. Gofirov, T. Karabaeva, In E3S Web of Conferences, 244, 02047 (2021)

4. R. A. Kulmatov, S. A. Adilov, S. Khasanov, In IOP Conference Series: Earth and Environmental Science, 614(1), 012149 (2020)

5. N. Ch. Namozov, D. A. Kodirova, M. I. Usmonova, International journal of scientific \& technology research, 9(03), 5491-5493 (2020)

6. B. B. Tuktashev, CH. Toshpulatov, I. Rakhmonov, B. Mavlonov, International Journal of Multidisciplinary Research, 42 (2020)

7. S. Isaev, S. Khasanov, Y. Ashirov, T. Karabaeva, A. Gofirov, In E3S Web of Conferences, 244, 02012 (2021)

8. B. Tuktashev, CH. Toshpulatov, M. Ajiniyazova, U. Gaziev, International Journal of Research Development, 11 (2020)

9. L. Gafurova, G. Djalilova, O. Ergasheva, D. Kadirova, Journal of Critical Reviews, 7(2), 283-287 (2020)

10. K. Khakimova, I. Musaev, A. Khamraliev, In E3S Web of Conferences, 227, 02003 (2021)

11. B. Sh. Matyakubov, Z. J. Mamatkulov, R. K. Oymatov, U. N. Komilov, G. E. Eshchanova, InterCarto, InterGIS, 26, 229-239 (2020)

12. N. Teshaev, B. Mamadaliyev, A. Ibragimov, S. Khasanov, InterCarto. InterGIS, 26(3), 324-333 (2020) 